\title{
Imaging of COVID-19 simulators
}

\author{
Abdelghany Mohammed Motawea, Suzan Omar and Rabab Yasin *i)
}

\begin{abstract}
Background: Coronavirus (COVID-19) pneumonia emerged in Wuhan, China, in December 2019. It was highly contagious spreading all over the world, with a rapid increase in the number of deaths. The reported cases have reached more than 14 million with more than 600,000 deaths around the world. So, the pandemic of COVID-19 became a surpassing healthcare crisis with an intensive load on the healthcare resources.

In this study, the aim was to differentiate COVID-19 pneumonia from its mimickers as atypical infection, interstitial lung diseases, and eosinophilic lung diseases based on $\mathrm{CT}$, clinical, and laboratory findings.

Results: This retrospective study included 260 patients, of which 220 were confirmed as COVID-19 positive by two repeated RT-PCR test and 40 were classified as non-COVID by two repeated negative RT-PCR test or identification of other pathogens, other relevant histories, or clinical findings.

In this study, 158 patients were male (60.7\%) and 102 patients were female (39.3\%). There was $60.9 \%$ of the COVID19 group were male and $39.1 \%$ were female. Patients in the non-COVID group were significantly older (the mean age was 46.4) than those in the confirmed COVID-19 group (35.2y). In the COVID-19 group, there was exposure history to positive cases in $84.1 \%$ while positive exposure history was 20\% in the non-COVID group.

Conclusion: The spectrum of CT imaging findings in COVID-19 pneumonia is wide that could be contributed by many other diseases making the interpretation of chest CTs nowadays challenging to differentiate between different diseases having the same signs and act as deceiving simulators in the era of COVID-19.
\end{abstract}

Keywords: COVID-19 coronavirus infections, CT computed tomography, Atypical pneumonia, Interstitial lung diseases

\section{Background}

In December 2019, the first case with acute lower respiratory tract infection caused by the novel coronavirus (nCoV-2019) was reported in China [1]. In March 11, 2020, the World Health Organization has announced that coronavirus disease 2019 (COVID-2019) is a pandemic and public health emergency of a global scope [2]. In April 8, 2020, the epidemic had reached to the whole earth countries, and the first million of infected humans had been reached [3].

Clinically, COVID-19 has variable presentations from an asymptomatic infection or mild upper respiratory tract symptoms to vigorous viral pneumonia with respiratory failure and even death [4].

\footnotetext{
*Correspondence: Rabab_yasin@outlook.com; Rababyasin123@gmail.com Radiology Department, Menofia University Faculty of Medicine, Menofia, Shibin Al Kawm, Egypt
}

At the time of writing these words, the reported cases have reached more than 14 million with more than 600 , 000 deaths around the world. So, the pandemic of COVID-19 became a surpassing healthcare crisis with an intensive load on the healthcare resources [5].

This rapid wide explosion of the pandemic was due to the lack of the early detection and control of the infection. Also, not all patients are tested, especially asymptomatic cases, or cases with mild symptoms. The primary standard of COVID-19 confirmation is the microbiological tests namely real-time polymerase chain reaction (RT-PCR) [6].

Computed tomography (CT) is used as an important complementary tool to RT-PCR for diagnosing COVID19 in this ongoing pandemic because these microbiological tests may be unavailable or slow in this emergency context [7].

\section{Springer Open}

(c) The Author(s). 2020 Open Access This article is licensed under a Creative Commons Attribution 4.0 International License, which permits use, sharing, adaptation, distribution and reproduction in any medium or format, as long as you give appropriate credit to the original author(s) and the source, provide a link to the Creative Commons licence, and indicate if changes were made. The images or other third party material in this article are included in the article's Creative Commons licence, unless indicated otherwise in a credit line to the material. If material is not included in the article's Creative Commons licence and your intended use is not permitted by statutory regulation or exceeds the permitted use, you will need to obtain permission directly from the copyright holder. To view a copy of this licence, visit http://creativecommons.org/licenses/by/4.0/. 
As RT-PCR may be insufficient, shortage of kits, falsely negative, extended processing period, or long mean time interval between initial negative and positive lab tests as well as its variable sensitivity ranging from 37 to $71 \%$, the chest CT shows a sensitivity of $97 \%$ in the diagnosis of COVID-19 [8].

So, the chest CT can play a main role in the early detection and management of COVID-19 pneumonia [6], especially for patients who have symptoms for more than 3 days [9].

Now, the systems of typical chest CT findings in COVID-19 have been established mainly involving the bilateral, peripheral, and basal predominant ground-glass opacities (GGOs) with or without consolidation with a peak of 9-13 days after the infection [10].

Also, atypical chest CT findings like central apical predominance, cavitations, masses, nodules, tree-in-buds, lymphadenopathy, and pleural thickening are included in the spectrum of imaging findings [11].

The spectrum of CT imaging findings in COVID-19 is wide and includes a lot of signs that could be contributed by many other diseases making the interpretation of chest CTs nowadays like an imitation game, for instance, not every GGO is a COVID-19, so it is a challenging to differentiate between different diseases having the same signs and act as deceiving simulators in the era of COVID-19.

In this study, the aim was to differentiate COVID-19 pneumonia from its mimickers based on CT findings, clinical, and laboratory details.

\section{Methods}

Two-hundred sixty patients were enrolled in this retrospective study in the period of the 30th of June and the 15th of August 2020. There were 158 males (60.7\%) and 102 females (39.3\%) with male to female distribution was 1.5:1.

All patients underwent high-resolution CT within 7 days after the onset of respiratory symptoms. Of those 260 patients, 220 cases of COVID-19 were confirmed with two consecutive positive PCR tests.

\section{Inclusion criteria include}

Patients presented with fever and/or respiratory symptoms within 7 days of CT examination and/or exposure history to confirmed cases or respiratory symptomrelated patient.

The clinical data including the age, sex, exposure history, nasopharyngeal swab results, and laboratory parameters of all patients were collected.

The study protocol was approved by the local ethics committee. All patients provided a written informed consent.

\section{CT image acquisition}

CT scans were performed within 7 days after symptom onset on a helical 64-slice CT Philips (parameters Kv 120 , mAs 200, field of view $350 \mathrm{~mm}$, thickness $0.67 \mathrm{~mm}$, increment $0.67 \mathrm{~mm}$ matrix 768 , scan time $5.6 \mathrm{~s}$ ). Image reconstruction was done at a slice thickness of $1-1.25$ $\mathrm{mm}$.

\section{CT image analysis}

The image analysis of each patient described:

- A number of lobes involved.

- Distribution characteristics of the lesions (e.g., peripheral distribution, central distribution, subpleural distribution, and posterior distribution).

- A pattern of the lesion (e.g., ground glass opacification (GGO) with or without consolidation, crazy-paving pattern, and the shape of the GGO).

- Associated signs in the lesion (e.g., bronchial and/or bronchiolar wall thickening), and tree-in-bud sign).

Based on the CT findings, the level of suspicion of COVID-19 infection is graded from very low or CORADS 1 up to very high or CO-RADS 5.

CORADS 1: The CT is normal or there are findings that indicate a non-infectious disease like congestive heart failure, sarcoid, histoplasmosis, malignancy, UIP, or fibrotic NSIP.

CORADS 2: Level of suspicion of COVID-19 infection is low. CT findings consistent with other infections like typical bronchiolitis with tree-in-bud and thickened bronchus walls.

CORADS 3: COVID-19 unsure or indeterminate. CT abnormalities indicating infection, but unsure whether COVID-19 is involved, like widespread bronchopneumonia, lobar pneumonia, and septic emboli with ground glass opacities

CORADS 4: The level of suspicion is high. Mostly, these are suspicious CT findings but not extremely typical:

- Unilateral ground glass

- Multifocal consolidations without any other typical finding

- Findings suspicious of COVID-19 in underlying pulmonary disease.

CORADS 5: The level of suspicion is very high. CT findings: bilateral GGO and consolidation, basal preference, vascular thickening, and subpleural bands. PCR is positive.

Patients with low CORADS score (1 to 3 ) and patients with CORADS 4 with negative PCR test were the main 
Table 1 Demographic data of the cases

\begin{tabular}{lll}
\hline Parameter & COVID confirmed cases & Low CORAD score and COVID non-confirmed cases \\
\hline Age & $35.2(22-61)$ & $46.4(10-63)$ \\
Gender & & \\
$\quad$ Male & $134=60.9 \%$ & $24=60 \%$ \\
$\quad$ Female & $86=39.1 \%$ & $16=40 \%$ \\
Exposure history & $185=84.1 \%$ & $8=20 \%$ \\
Duration between symptoms and CT imaging & $3(1-6)$ days & $5(1-7)$ \\
\hline
\end{tabular}

concern. All clinical and laboratory data were meticulously analyzed to reach the final diagnosis.

Three experienced radiologists (20 and 15 years of experience) independently reviewed all the scans. There was a perfect inter-observer agreement between the readers as regards CORADS scoring of the cases $(K=0.83)$.

\section{Statistical analysis}

Inter-observer agreement analysis was performed by the Cohen coefficient was to determine segmental lesion detection consistency among observers. Values were interpreted on the basis of the convention by Landis and Koch as follows: Kappa agreement 0 less than chance agreement, $0.01-0.20$ slight agreement, $0.21-0.40$ fair agreement, $0.41-0.60$ moderate agreement, $0.61-0.80$ substantial agreement, and 0.81-0.99 almost perfect agreement.

\section{Results}

This retrospective study included 260 patients, of which 220 were confirmed as COVID-19 positive by two repeated RT-PCR test, and 40 were classified as nonCOVID by two repeated negative RT-PCR tests or identification of other pathogens, other relevant histories, or clinical findings.

In this study, 158 patients were male (60.7\%) and 102 patients were female (39.3\%). There were $60.9 \%$ of the
COVID-19 group who were male and 39.1\% who were female. Patients in the non-COVID group were significantly older (the mean age was 46.4) than those in the confirmed COVID-19 group (35.2 years). In the COVID-19 group, there was exposure history to positive cases in $84.1 \%$ while positive exposure history was $20 \%$ in the non-COVID group.

The duration between the start of symptoms and CT imaging was about 3 days in the COVID-19 group and about 5 days in the non-COVID group (Table 1).

The most presenting symptoms (Table 2) in the COVID-19 group were fever (95.4\%) and cough (92.7\%) while the most presenting symptom in the non-COVID group was cough in $92.5 \%$.

In the non-COVID group, 55\% had a high leucocytic count; however, in the COVID-19 group, $76.4 \%$ had a low leucocytic count. COVID-19 patients had a high ferritin level (86.4\%) and high a D-dimer level (97.1\%); however, the non-COVID group had predominant normal ferritin level (72.5\%) and normal D-dimer (95\%) (Table 3).

\section{CT imaging findings (Table 4)}

A high-resolution CT chest was done for all 260 examined patients. GGO with or without consolidation was the constant imaging feature seen in both groups. Rounded GGO was more prominent in the COVID-19 group ( $n=194,88.2 \%)$. Bilateral involvement with

Table 2 Clinical presentation of the cases

\begin{tabular}{|c|c|c|c|c|}
\hline \multirow[t]{2}{*}{ Presenting symptoms } & \multicolumn{2}{|c|}{ COVID confirmed cases } & \multicolumn{2}{|c|}{ Low CORAD score and COVID non-confirmed cases } \\
\hline & $n=220$ & $\%$ & $n=40$ & $\%$ \\
\hline Fever & 210 & 95.4 & 25 & 62.5 \\
\hline Cough & 204 & 92.7 & 37 & 92.5 \\
\hline Sputum & 60 & 27.3 & 33 & 82.5 \\
\hline Runny nose & 170 & 77.3 & 16 & 40 \\
\hline Loss of smell and taste & 190 & 86.4 & 5 & 12.5 \\
\hline Chest pain/tightness & 168 & 76.4 & 28 & 70 \\
\hline Sore throat & 148 & 67.3 & 3 & 7.5 \\
\hline Diarrhea and abdominal pain & 126 & 57.3 & 2 & 5 \\
\hline Fatigue and muscle pain & 180 & 81.8 & 14 & 35 \\
\hline hemoptysis & 0 & 0 & 1 & 0.025 \\
\hline
\end{tabular}


Table 3 Laboratory finding in the cases

\begin{tabular}{|c|c|c|c|c|}
\hline \multirow{2}{*}{$\begin{array}{l}\text { Laboratory } \\
\text { finding }\end{array}$} & \multicolumn{2}{|c|}{ COVID confirmed cases } & \multicolumn{2}{|c|}{ Low CORAD score and COVID non-confirmed cases } \\
\hline & $n=220$ & $\%$ & $n=40$ & $\%$ \\
\hline \multicolumn{5}{|c|}{ Leucocytic count } \\
\hline High & 16 & 7.3 & 22 & 55 \\
\hline Low & 168 & 76.3 & 11 & 27.5 \\
\hline Normal & 36 & 16.4 & 7 & 17.5 \\
\hline \multicolumn{5}{|l|}{ Ferritin } \\
\hline High & 190 & 86.4 & 4 & 10 \\
\hline Low & 10 & 4.5 & 7 & 17.5 \\
\hline Normal & 20 & 9.1 & 29 & 72.5 \\
\hline \multicolumn{5}{|l|}{ d-dimer } \\
\hline High & 174 & 79.1 & 2 & 5 \\
\hline Low & 14 & 6.4 & - & 0 \\
\hline Normal & 32 & 14.5 & 38 & 95 \\
\hline
\end{tabular}

peripheral and lower lobe predominance was more evident in the COVID-19 group. Bronchial wall thickening and central predominance were more prominent in the non-COVID group $(42.5 \%$ and $27.5 \%$, respectively). Tree-in-bud opacity and cavitations were seen only in the non-COVID group. Table 5 representing the diagnostic clues for COVID-19 mimicker based on CT, laboratory, and clinical findings.

\section{Discussion}

COVID-19 pandemic is a severe and easily transmissible disease exploding all around the world. Chest CT scans play an essential role in the initial and early diagnosis of COVID-19 as it can show positive findings before the initial positive RT-PCR. So, it is important to focus on baseline
CT findings and radiologists' capabilities to differentiate between non-COVID and COVID-19 in the first consultation to provide proper isolation and treatment [12].

Bai et al. [13] cited that radiologists were capable of differentiating COVID-19 from other viral pneumonias by chest $\mathrm{CT}$ with high specificity and moderate or varying specificity (24-94\%) among 7 different readers from the USA and China, but an easy simple understood system is still needed especially in epidemic areas with poor medical resources and expert radiologists. According to previous studies, COVID-19 is more likely to present with some CT image features compared to non-COVID19 diseases.

All studies indicate that the main CT feature of COVID-19 pneumonia is the presence of ground-glass

Table 4 CT findings in all cases

\begin{tabular}{|c|c|c|c|c|c|}
\hline \multirow[t]{2}{*}{ CT imaging findings } & \multicolumn{2}{|c|}{ COVID confirmed cases } & \multicolumn{2}{|c|}{ Low CORAD score and COVID non-confirmed cases } & \multirow[t]{2}{*}{ Total } \\
\hline & $n=220$ & $\%$ & $n=40$ & $\%$ & \\
\hline Bilateral involvement & 210 & 95.5 & 31 & 77.5 & 241 \\
\hline Peripheral distribution & 188 & 85.5 & 22 & 55 & 210 \\
\hline Lower lobe predominance & 210 & 95.5 & 28 & 70 & 238 \\
\hline Ground glass +/- consolidation & 220 & 100 & 40 & 100 & 260 \\
\hline Rounded ground glass opacities & 194 & 88.2 & 3 & 7.5 & 197 \\
\hline Crazy paving & 172 & 78.2 & 4 & 10 & 176 \\
\hline Subpleural bands & 148 & 67.3 & 12 & 30 & 160 \\
\hline One lobe involvement & 6 & 2.7 & 5 & 12.5 & 11 \\
\hline Central predominance & 14 & 6.4 & 11 & 27.5 & 25 \\
\hline Tree in bud & 0 & 0 & 12 & 30 & 12 \\
\hline Bronchial wall thickening & 44 & 20 & 17 & 42.5 & 61 \\
\hline cavitation & 0 & 0 & 5 & 12.5 & 5 \\
\hline Pleural effusion & 4 & 1.8 & 12 & 30 & 16 \\
\hline
\end{tabular}


Table 5 Diagnostic clues for COVID-19 mimicker

\begin{tabular}{|c|c|c|c|c|c|c|}
\hline \multirow{2}{*}{\multicolumn{2}{|c|}{ Final diagnosis }} & \multicolumn{4}{|c|}{ Diagnostic clues } & \multirow[t]{2}{*}{ Number of cases } \\
\hline & & $\begin{array}{l}\text { Clinical } \\
\text { history }\end{array}$ & $\begin{array}{l}\text { Pleural/cardiac } \\
\text { involvement }\end{array}$ & $\begin{array}{l}\text { Pulmonary parenchymal } \\
\text { involvement }\end{array}$ & Laboratory/biopsy & \\
\hline \multicolumn{2}{|c|}{ Bronchial asthma } & $\begin{array}{l}\text { History of } \\
\text { bronchial } \\
\text { asthma }\end{array}$ & & $\begin{array}{l}\text { Emphysematous changes } \\
\text { Subpleural sparing } \\
\text { Bronchiactasis } \\
\text { Peribronchial thickening } \\
\text { Centrilobular nodules due } \\
\text { to superadded infection }\end{array}$ & & 3 \\
\hline \multirow[t]{3}{*}{$\begin{array}{l}\text { Eosinophilic } \\
\text { lung }\end{array}$} & $\begin{array}{l}\text { Churg-Strauss } \\
\text { syndrome }\end{array}$ & $\begin{array}{l}\text { History of } \\
\text { bronchial } \\
\text { asthma, } \\
\text { sinusitis }\end{array}$ & Pleural effusion & & Peripheral eosinophilia & 1 \\
\hline & $\begin{array}{l}\text { Drug rash with } \\
\text { eosinophilia and } \\
\text { systemic symptoms } \\
\text { (DRESS) syndrome }\end{array}$ & $\begin{array}{l}\text { Clinical } \\
\text { history, skin } \\
\text { rash }\end{array}$ & Pleural effusion & & Peripheral eosinophilia & 1 \\
\hline & Loffler syndrome & & & Fleeting opacities & $\begin{array}{l}\text { Peripheral blood } \\
\text { eosinophilia and high } \\
\text { IgE level } \\
\text { Elevated eosinophilic } \\
\text { count on bronchoalveolar } \\
\text { lavage }\end{array}$ & 1 \\
\hline $\mathrm{H} 1 \mathrm{~N} 1$ & & & & & $\begin{array}{l}\text { PCR test revealed } \mathrm{HINI} \\
\text { virus }\end{array}$ & 1 \\
\hline ARDS & & $\begin{array}{l}\text { Clinical } \\
\text { criteria }\end{array}$ & & $\begin{array}{l}\text { Bilateral basal dense } \\
\text { consolidation on a } \\
\text { background of diffuse GGO } \\
\text { in the non-dependent re- } \\
\text { gions with bronchial dilata- } \\
\text { tion in GGO and crazy } \\
\text { paving appearance }\end{array}$ & & 3 \\
\hline \multicolumn{2}{|c|}{ Hypersensitivity pneumonitis } & $\begin{array}{l}\text { Clinical } \\
\text { history of } \\
\text { exposure to } \\
\text { antigen (Bird } \\
\text { Fancier's } \\
\text { Disease) } \\
\text { Reproduction } \\
\text { of symptoms } \\
\text { following } \\
\text { exposure }\end{array}$ & & $\begin{array}{l}\text { Poorly defined centrilobular } \\
\text { nodules } \\
\text { Headcheese lung in } \\
\text { subacute phase }\end{array}$ & $\begin{array}{l}\text { Lymphocytosis on } \\
\text { bronchoalveolar lavage }\end{array}$ & 4 \\
\hline \multicolumn{2}{|l|}{ RB-ILD } & $\begin{array}{l}\text { History of } \\
\text { smoking } \\
\text { No fever }\end{array}$ & & $\begin{array}{l}\text { Ground-glass opacities and } \\
\text { centrilobular nodules }\end{array}$ & $\begin{array}{l}\text { Bronchoalveolar lavage } \\
\text { (BAL) findings (the } \\
\text { presence of smokers' } \\
\text { macrophages and the } \\
\text { absence of lymphocytosis) } \\
\text { Proved by biopsy }\end{array}$ & 2 \\
\hline \multicolumn{2}{|c|}{ Amiodarone lung } & $\begin{array}{l}\text { History of } \\
\text { drug intake }\end{array}$ & & $\begin{array}{l}\text { Peripheral patches } \\
\text { Pulmonary nodules and } \\
\text { septal thickening }\end{array}$ & $\begin{array}{l}\text { Fiberoptic bronchoscopy } \\
\text { with BAL and } \\
\text { transbronchial biopsy }\end{array}$ & 1 \\
\hline \multicolumn{2}{|c|}{$\begin{array}{l}\text { SLE with diffuse alveolar } \\
\text { hemorrhage }\end{array}$} & $\begin{array}{l}\text { History of SLE, } \\
\text { hemoptysis. }\end{array}$ & & $\begin{array}{l}\text { Upper lobe predominance, } \\
\text { confluent consolidation } \\
\text { sparing costophrenic angles } \\
\text { and the lung periphery. }\end{array}$ & & 1 \\
\hline \multicolumn{2}{|l|}{ Trauma } & $\begin{array}{l}\text { History of } \\
\text { recent trauma }\end{array}$ & Pneumothorax & & & 5 \\
\hline \multirow{2}{*}{$\begin{array}{l}\text { Atypical } \\
\text { bacterial } \\
\text { infection }\end{array}$} & $\begin{array}{l}\text { Mycoplasma } \\
\text { bronchopneumonia }\end{array}$ & & Pleural effusion & $\begin{array}{l}\text { Peribronchial thickening, } \\
\text { confined to lobes }\end{array}$ & & 1 \\
\hline & Staph-penumonia & & & $\begin{array}{l}\text { GGO peribronchial } \\
\text { thickening and } \\
\text { pneumatocele }\end{array}$ & & 1 \\
\hline
\end{tabular}


Table 5 Diagnostic clues for COVID-19 mimicker (Continued)

\begin{tabular}{|c|c|c|c|c|c|}
\hline \multirow[t]{2}{*}{ Final diagnosis } & \multicolumn{4}{|c|}{ Diagnostic clues } & \multirow[t]{2}{*}{ Number of cases } \\
\hline & $\begin{array}{l}\text { Clinical } \\
\text { history }\end{array}$ & $\begin{array}{l}\text { Pleural/cardiac } \\
\text { involvement }\end{array}$ & $\begin{array}{l}\text { Pulmonary parenchymal } \\
\text { involvement }\end{array}$ & Laboratory/biopsy & \\
\hline $\begin{array}{l}\text { Other bacterial } \\
\text { pneumonia }\end{array}$ & & & $\begin{array}{l}\text { Unilateral lung affection } \\
\text { Tree in bud } \\
\text { Bronchiectasis }\end{array}$ & & 6 \\
\hline Alveolar sarcoid & $\begin{array}{l}\text { History of } \\
\text { sarcoid } \\
\text { No fever }\end{array}$ & & $\begin{array}{l}\text { Upper lobe affection, } \\
\text { peribronchial thickening, } \\
\text { mediastinal lymph nodes }\end{array}$ & & 1 \\
\hline Acute Interstitial Pneumonia & $\begin{array}{l}\text { Acute } \\
\text { symptoms } \\
\text { like ARDS }\end{array}$ & & $\begin{array}{l}\text { Bilateral asymmetric } \\
\text { confluent GGO with } \\
\text { consolidative patches more } \\
\text { in the lower lobes }\end{array}$ & $\begin{array}{l}\text { Proved by transbronchial } \\
\text { biopsy }\end{array}$ & 1 \\
\hline $\begin{array}{l}\text { Cryptogenic organizing } \\
\text { pneumonia }\end{array}$ & & Pleural effusion & $\begin{array}{l}\text { Atoll sign } \\
\text { Subpleural sparing }\end{array}$ & $\begin{array}{l}\text { Confirmed by } \\
\text { histopathological } \\
\text { correlation }\end{array}$ & 2 \\
\hline Pulmonary alveolar proteinosis & & & $\begin{array}{l}\text { Asymmetric lung } \\
\text { involvement with crazy } \\
\text { paving appearance }\end{array}$ & $\begin{array}{l}\text { Confirmed by } \\
\text { bronchoalveolar lavage }\end{array}$ & 1 \\
\hline $\begin{array}{l}\text { Metastatic Calcifications with } \\
\text { renal failure }\end{array}$ & $\begin{array}{l}\text { History of } \\
\text { renal failure }\end{array}$ & & $\begin{array}{l}\text { High-density centrilobular } \\
\text { ground glass nodules with } \\
\text { superadded infection }\end{array}$ & & 1 \\
\hline Cardiogenic pulmonary edema & $\begin{array}{l}\text { Clinical } \\
\text { history }\end{array}$ & $\begin{array}{l}\text { Enlarged cardiac } \\
\text { size }+/- \\
\text { pericardial } \\
\text { effusion, dilated } \\
\text { pulmonary trunk, } \\
\text { bilateral pleural } \\
\text { effusion, }\end{array}$ & $\begin{array}{l}\text { Thickened interlobular } \\
\text { septal, peri-lymphatic, and } \\
\text { peribronchovascular } \\
\text { thickening } \\
\text { Perihilar distribution of } \\
\text { ground glass opacities (bat } \\
\text { wing) }\end{array}$ & & 3 \\
\hline
\end{tabular}

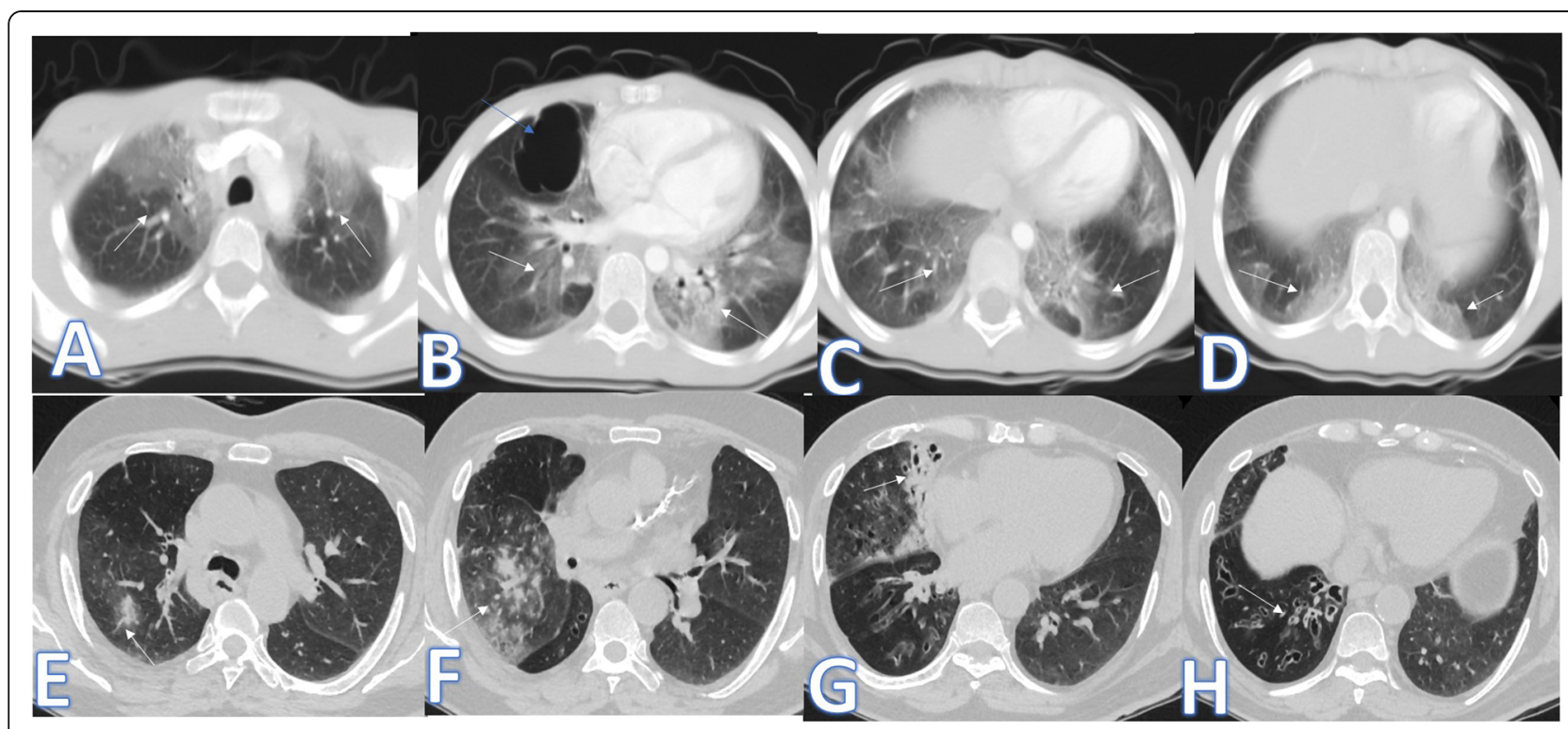

Fig. 1 A 10-year-old male patient with fever and cough. CT (a-d) showed bilateral scattered ground glass patches more central than peripheral (white arrows) with large pneumatocele at the medial segment of the right middle lobe (blue arrow). The diagnosis was staph pneumonia. A 45year-old male patient with cough and fever. CT (e-h) showed unilateral right lung consolidative patch with tree-in bud appearance and ground glass appearance (arrows in $\mathbf{e}$ and $\mathbf{f}$ ) with cylindrical bronchiectasis at the middle and lower lobes (arrows in $\mathbf{g}$ and $\mathbf{h}$ ) and peribronchial thickening. The diagnosis was bacterial pneumonia 


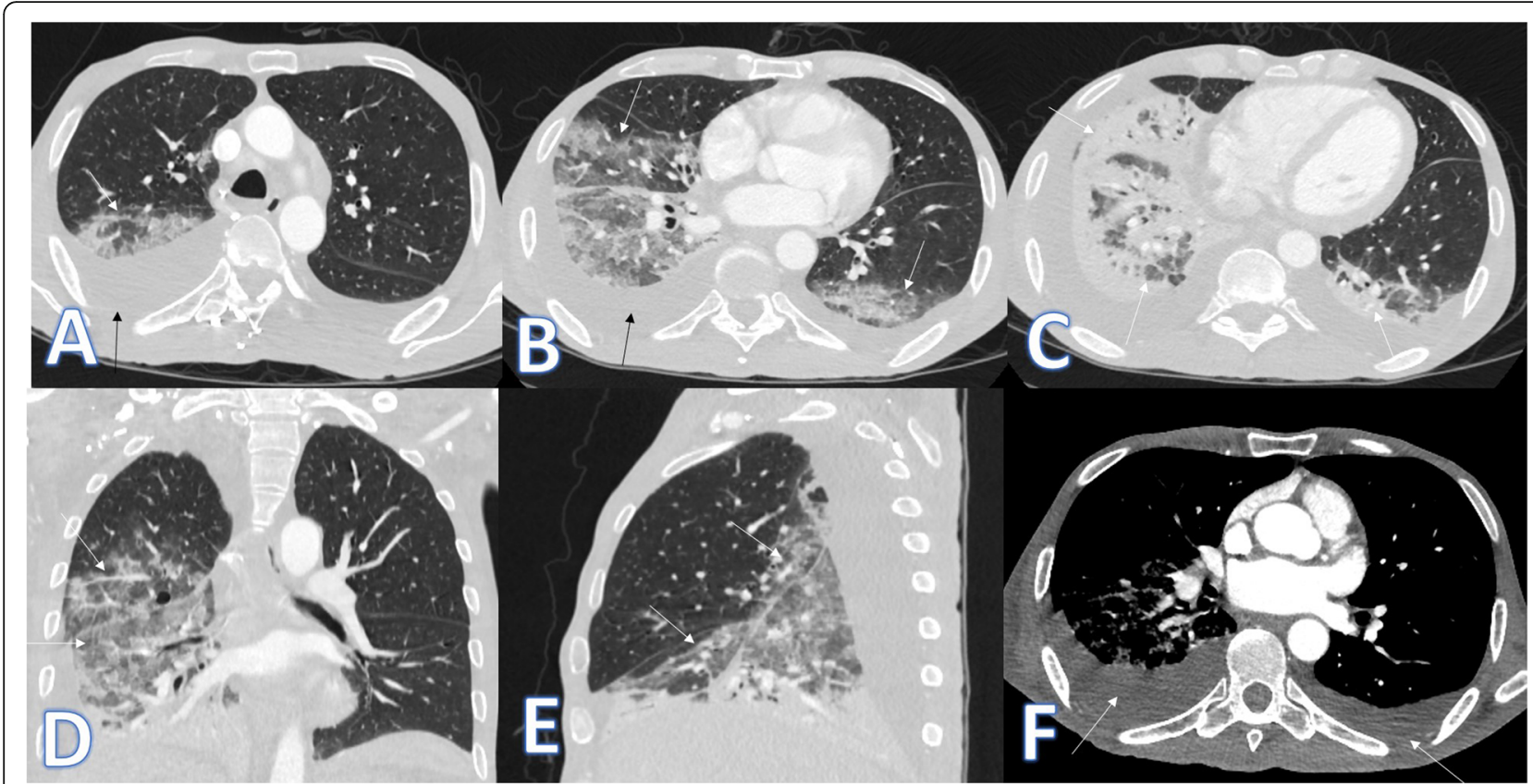

Fig. 2 A 53-year-old male patient with cough and dyspnoea. CT showed multiple consolidative patches with ground glass appearance involving the whole right lower lobe, lateral segment of the middle lobe, and superior and posterior segments of the left lower lobe with bilateral pleural effusions (arrows). The diagnosis was mycoplasma pneumoniae

opacities (GGO), typically with a peripheral and subpleural distribution. The multiple lobes involvement with basal predominance is reported in the majority of cases with COVID-19 [10].

GGO can result from various pathologies of alveolar filling with water, pus, protein, blood, or cells including viral infections, like COVID-19, as well as bacterial infections [1].
In their study, Luo et al. [14] added some negative points to make a hierarchical diagnosis. As the most of the reported COVID-19 cases show affection of more than 2 lobes of the lungs, only one lobe involvement is considered as a negative scoring point and also the single-lobe affection has been reported in some cases of communityacquired pneumonia.

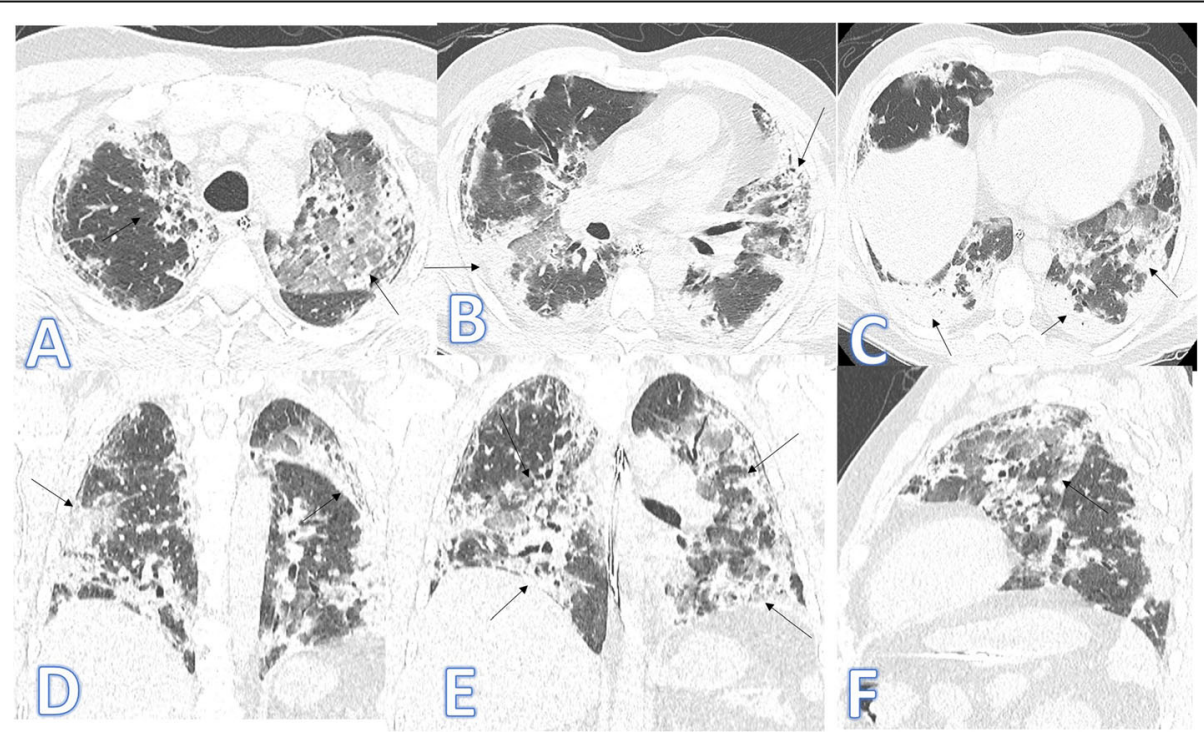

Fig. 3 A 59-year-old male with cough, desaturation with fever. CT chest showed bilateral confluent consolidative patches with GGO and crazy paving appearance (arrows), and it was proven H1N1 on PCR test 


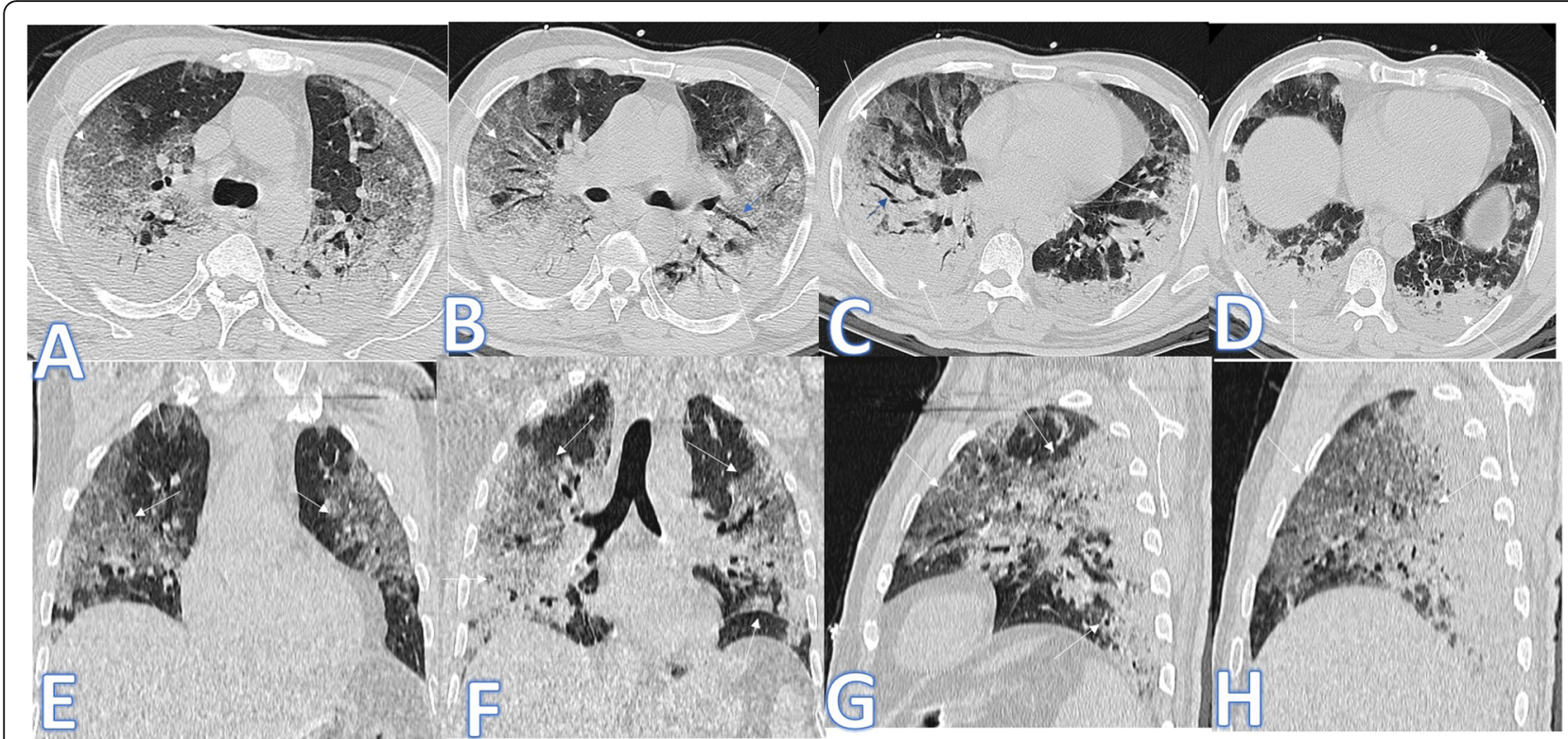

Fig. 4 A 68-year-old male patient with septicemia, presented with fever and cough. CT showed bilateral basal dense consolidations on background of GGO in the anterior non-dependent portions of the lungs and crazy paving appearance (white arrows) with bronchial dilatation in the ground glass opacities (small blue arrows) with no pleural effusion, and the diagnosis was ARDS

Many things in the lungs look exactly the same, and due to the tens of entities that contribute to GGO and/ or consolidation, it is critical to understand the new and sometimes puzzling clinical presentations emerging in the current COVID-19 pandemic and it is important to have at hand concepts of non-COVID-19 conditions that act as "mimics and chameleons" of the COVID-19 pneumonia.

One of the major differentials of COVID-19 pneumonia is the pneumonia from other infectious causes like bacterial origin. Community-acquired pneumonia is usually characterized by an airspace consolidation affecting one segment or lobe, limited by the pleural surfaces. CT may also show ground-glass pattern, centrilobular nodules, bronchial thickening, and/or mucoid impaction. In the absence of superinfection, COVID-19 pneumonia has very different findings, with no centrilobular nodules or mucoid impactions [15].

In this study, there were 8 cases of atypical bacterial pneumonias, and they showed GGO with consolidative patches like COVID-19, but there were other features rarely seen in COVID-19. A large pneumatocele is seen in staph pneumonia (Fig. 1), unilateral lung affection with consolidative patch and tree-in-bud appearance with cylindrical bronchiectasis (Fig. 1). Also, consolidation confined to the lobes with peribronchial thickening and pleural effusion in Mycoplasma pneumoniae (Fig. 2). There was one case of CT feature typical to COVID-19. CT chest showed bilateral confluent consolidative patches with GGO and crazypaving appearance, and it was proven $\mathrm{H} 1 \mathrm{~N} 1$ on PCR test (Fig. 3).

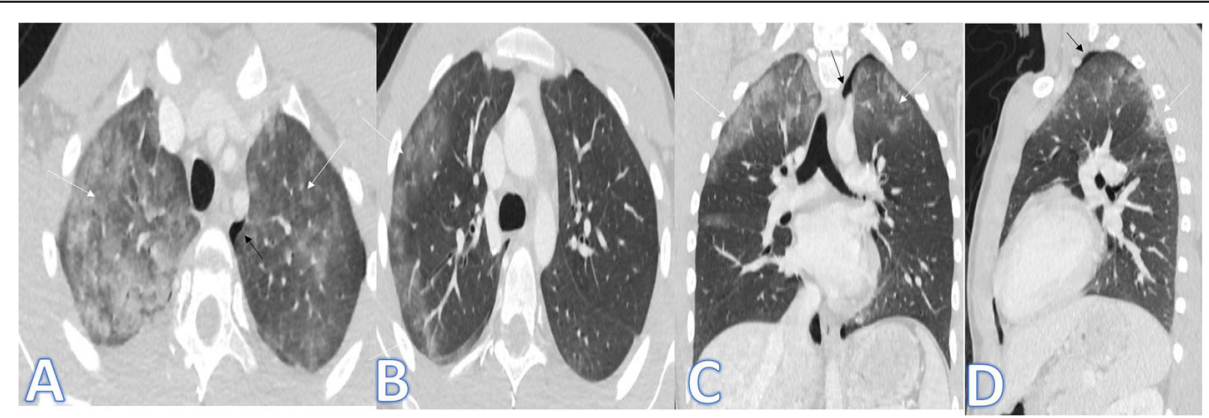

Fig. 5 A 19-year-old male patient presented with chest tightness after trauma. He had a history of trauma 1 day ago. CT chest showed bilateral GGO at both the upper lobes and right lower lobes with peripheral predilection (white arrows), the thin rim of the left pneumothorax (black arrow) was seen on the left side, and the diagnosis was post-traumatic pulmonary contusions 


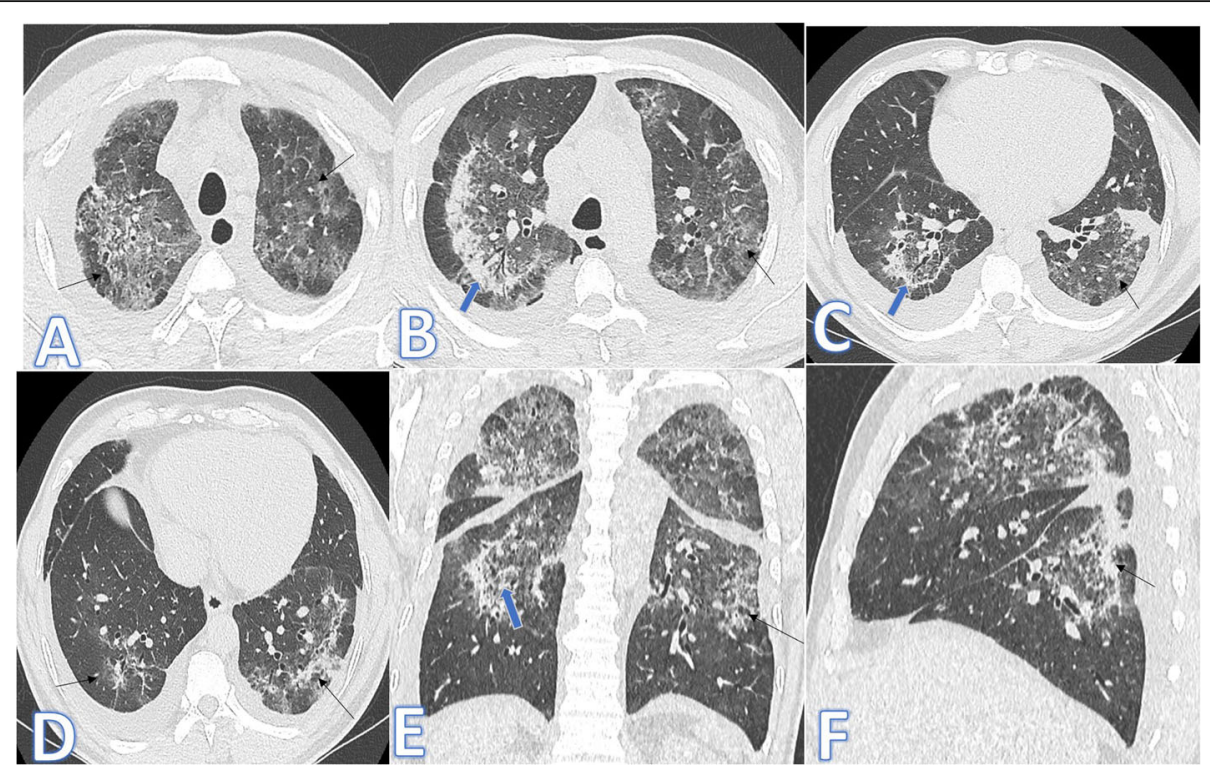

Fig. 6 A 61-year-old male patient presented with cough and fever. CT chest showed multifocal GGO, crazy paving and consolidation with Atoll sign (blue arrows) more in the upper lobes with subpleural sparing and bilateral pleural effusions more on the right side (arrow in $\mathbf{d}$ ). The diagnosis was COP, confirmed by histopathology

Elicker et al. [16] and Grudzinska et al. [17] stated that in the current epidemic, GGO in patients with fever and respiratory symptoms suggests COVID-19 until proved otherwise, but some pneumonias of other viral causes may show some different signs like H1N1 influenza, with bronchial wall thickening, centrilobular nodules, and a distribution more along the bronchovascular bundles. Pleural effusion, pneumothorax/pneumomediastinum may be present.

There are broad spectra of non-infectious conditions that cause diffuse GGO. In this study, there were 3 cases of cardiac pulmonary edema with cardiomegaly, dilated pulmonary trunk, interlobular septal and peribronchovascular thickening, pleural effusions, and perihilar distribution of ground-glass opacities.

Komiya et al. [18] stated that pulmonary edema (cardiogenic and non-cardiogenic) is one of the most common causes of diffuse GGO characterized by central predominance with sparing of the peripheral portions of the lung contrary to COVID-19. It is associated with other suggestive signs such as bronchovascular bundle

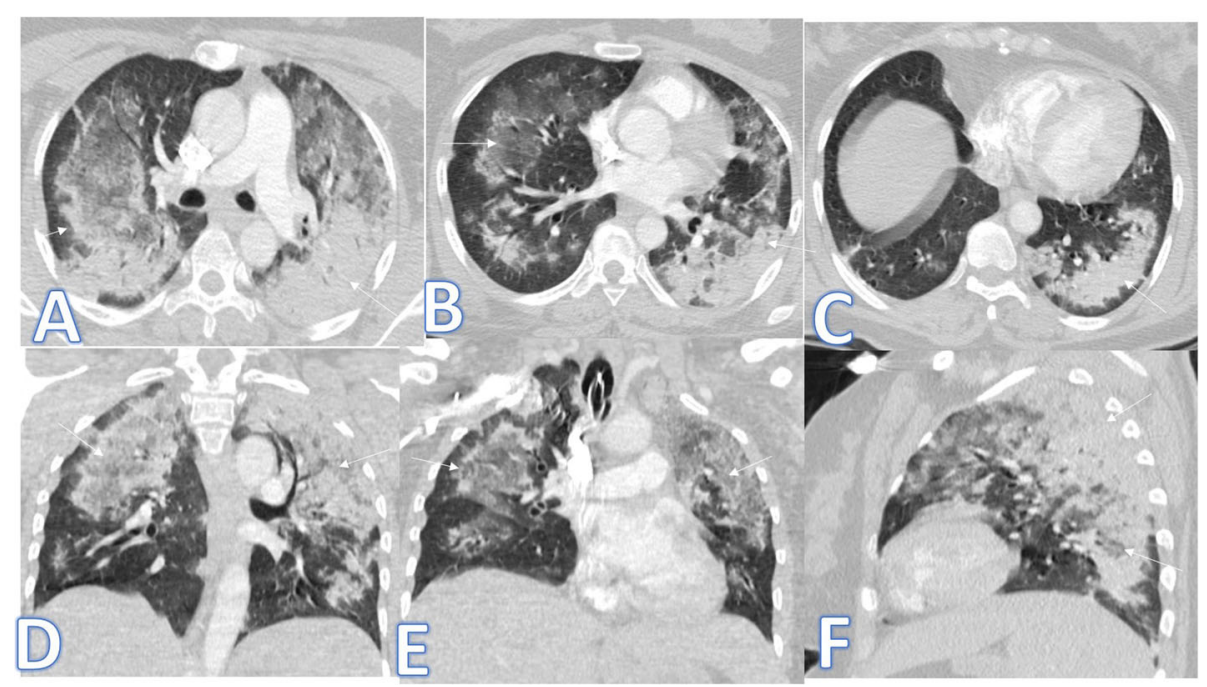

Fig. 7 A 46-year-old female patient with SLE, presented with hemoptysis. CT showed bilateral confluent consolidative patches with GGO (arrows) more predominant in the upper lobes with subpleural and costophrenic angle sparing. The diagnosis was diffuse alveolar hemorrhage 


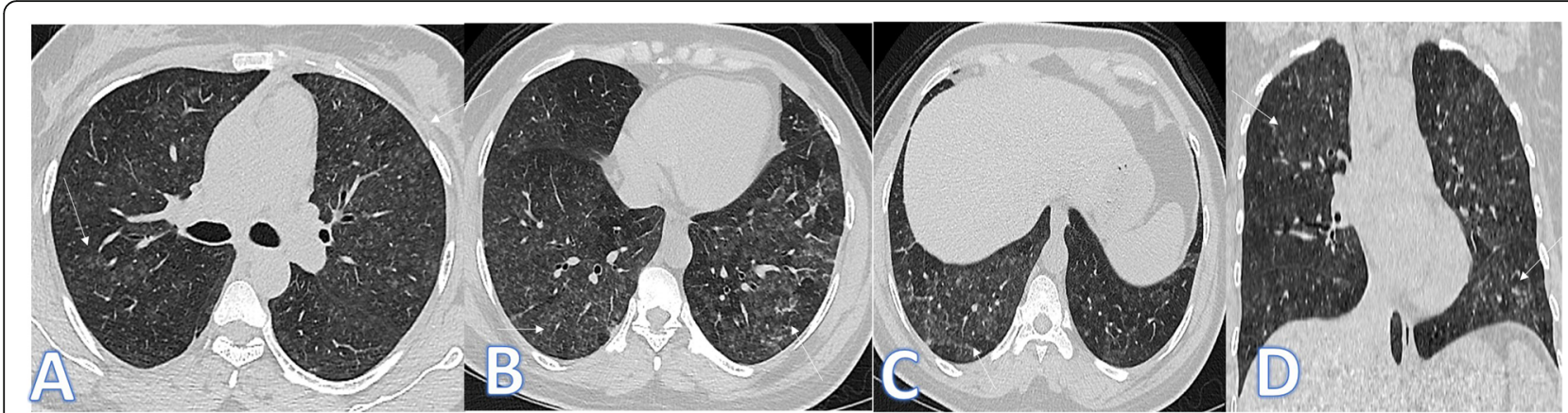

Fig. 8 A 46-year-old female patient with acute HP presented with fever and cough. CT chest showed bilateral scattered centrilobular nodules with bilateral lower lobe GGO (arrows). No fibrosis seen

thickening, interlobular septal thickening, and pleural effusions.

In this study, there were 3 cases of ARDS, and the diagnosis was based on acute clinical criteria and imaging features of bilateral basal extensive consolidation on the background of GGO in the anterior nondependent portions of the lungs with bronchial dilatation in the ground glass opacities and crazy-paving appearance (Fig. 4).

Zompatori et al. [19] and Ferguson et al. [20] described acute respiratory distress syndrome (ARDS) diagnosis is based mainly on clinical criteria include lung injury of acute onset, within 1 week of an apparent clinical insult and with the progression of respiratory symptoms, respiratory failure not explained by heart failure or volume overload and decreased arterial $\mathrm{PaO}_{2} / \mathrm{FiO}_{2}$ ratio. According to the phase of the disease, in the early phase, CT imaging shows pulmonary opacification: with anteroposterior density gradient with basal dense consolidation on a background of diffuse GGO with normal or hyperexpanded lung in the non-dependent regions.

In this study, there were 5 cases of pulmonary contusions following trauma, they showed scattered GGO, the clue for the diagnosis was the clinical history with the presence of a thin rim of pneumothorax in 2 cases (Fig. 5).

Oikonomou et al. [21] stated that pulmonary contusions follow blunt or penetrating chest trauma and are almost always seen with other chest (and abdominal) injuries, typically seen as focal, non-segmental areas of parenchymal opacification, more common posteriorly, and in the lower lobes usually peripheral. The clinical history of trauma is always a distinguishing feature.

Wallis et al. [22] stated that some of interstitial lung disease (ILD) also involve the alveolar spaces that make an overlap with COVID-19 pneumonia. This includes COP, HP, RB-ILD, sarcoid, PAP, vasculitis, rheumatoid disease, and drug-induced.

In this study, there were 2 cases of cryptogenic organizing pneumonia with multifocal GGO, crazy-paving and consolidation with atoll sign more in the upper lobes and bilateral pleural effusions (Fig. 6). They were mimickers to COVID-19 pneumonia with histopathological results that were helpful for the final diagnosis.

Webb et al. [23] described that the most common HRCT features of cryptogenic organizing pneumonia (COP) with multifocal ground glass opacifications, crazy-paving and/or consolidation, small, ill-defined nodules, bronchial wall thickening, or dilatation. He

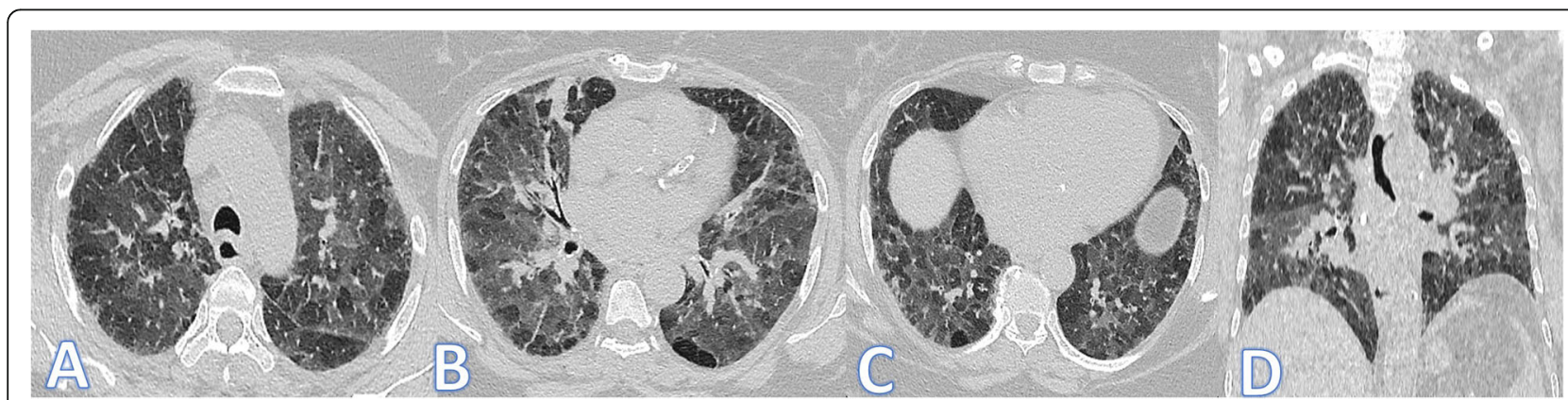

Fig. 9 A 64-year-old female axial and coronal CT image shows the headcheese sign, featuring sharp geographic margination along the edges of the secondary pulmonary lobules with three distinct levels of attenuation representing normal, ground glass, and hyperinflated regions of lung. The diagnosis was subacute HP 


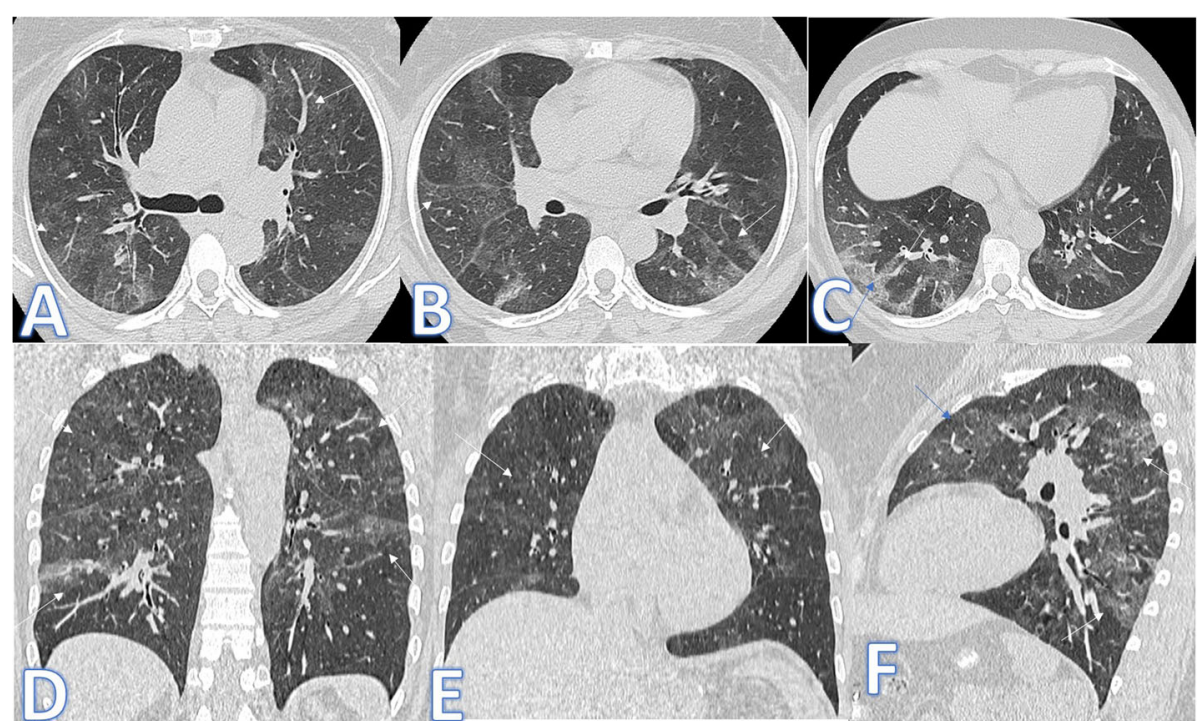

Fig. 10 A 45-year-old male patient presented with cough and dyspnea. CT showed bilateral patches of GGO in both lobes (white arrows) with crazy paving seen in both lower lobes (blue arrow); the diagnosis was RB-ILD proven by biopsy

stated that the reverse halo sign (atoll sign) is seen only in $20 \%$ of patients, and it is not considered to be highly specific.

In the current study, there was one case of diffuse alveolar hemorrhage (Fig. 7) with a patient known of SLE and presented with hemoptysis. The predominance of GGO in the upper lobes with subpleural and costophrenic angle sparing as well as the clinical history was the diagnostic clues.

Marten et al. [24] describe intra-alveolar hemorrhage secondary to extensive parenchymal small-vessel vasculitis like that caused by connective tissue disorders like systemic lupus erythematosus (SLE) which is typically diffuse and initially causes more widespread lobular ground-glass opacification with gravity-dependent density progressing to air-space consolidation +/- crazypaving pattern.

In this study, there were 4 cases of hypersensitivity pneumonitis of both acute (Fig. 8) and subacute phases (Fig. 9). The diagnosis was made by the clinical history of exposure to antigen (Bird Fancier's Disease), radiological findings with small poorly defined centrilobular nodules, ground-glass appearance in the acute phase or

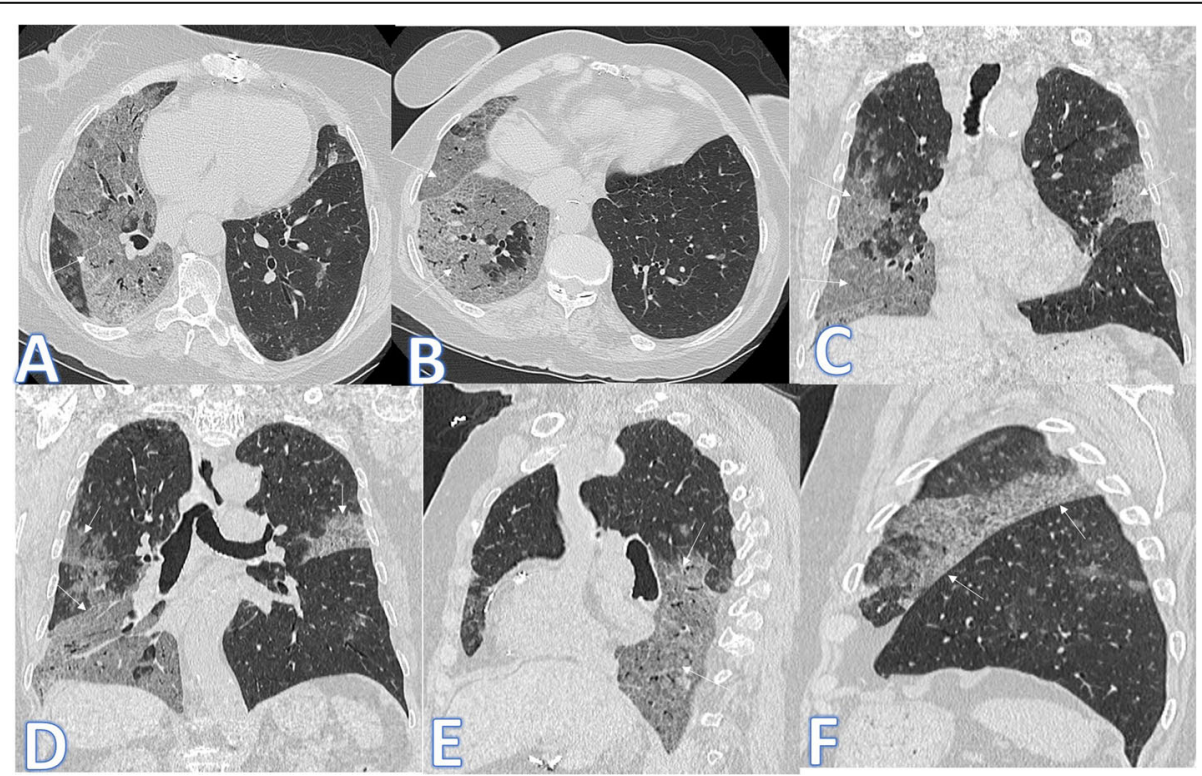

Fig. 11 A 80-year-old female patient presented with cough. CT showed bilateral asymmetrical GGO with crazy paving appearance (arrows) near totally involving the right middle and lower lobes with less involvement of the left lung. The diagnosis was PAP 


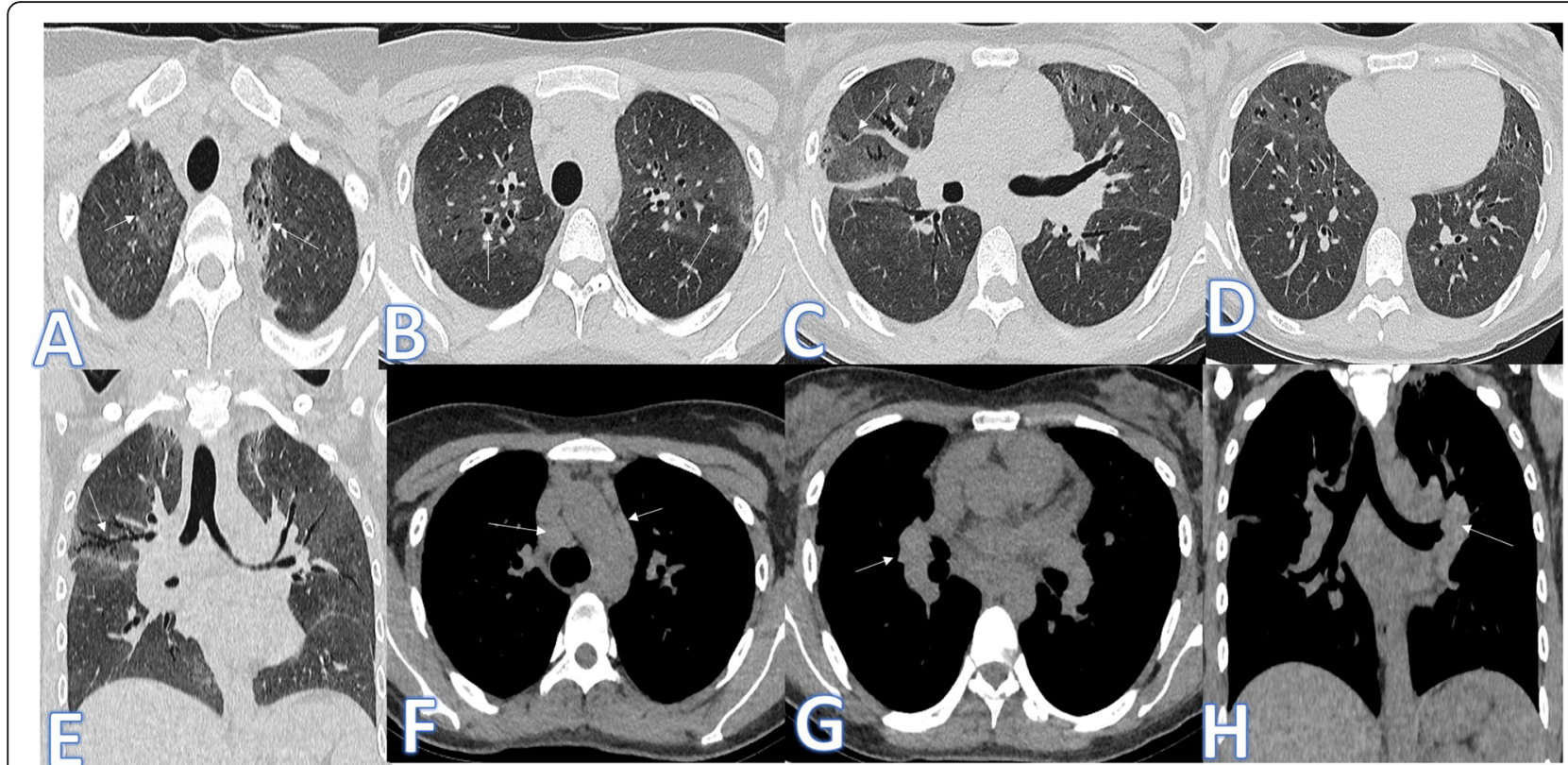

Fig. 12 A 30-year-old female patient known of sarcoid disease presented with cough; there was bilateral patchy ground glass appearance with mild bronchiectatic changes (arrows) and fibrotic changes of the upper lobe predilection. Multiple enlarged prevascular, pre/paratracheal, and hilar LNS was seen in mediastinal window (arrows in $\mathbf{f}-\mathbf{h}$ )

headcheese sign in the subacute phase, lymphocytosis on bronchoalveolar lavage, and reproduction of symptoms following exposure.

Lacasse et al. [25] described that acute hypersensitivity pneumonitis or acute extrinsic allergic alveolitis is usually occurring within few hours after antigen exposure and often recurs with the re-exposure and has the potential to resolve with treatment. In the acute phase, chest CT shows bilateral and symmetric homogeneous GGO (alveolitis) with multiple centrilobular opacities: usually $<5 \mathrm{~mm}$ in diameter also may be present with no fibrosis [26].
There were two cases of RB-ILD in this study presented by cough, dyspnea, and shortness of breath. Both were heavy smokers. The diagnosis was made by clinical history of smoking, typical HRCT findings of groundglass opacities, and centrilobular nodules (Fig. 10) and proved by biopsy in the first case and bronchoalveolar lavage (BAL) findings (the presence of smokers' macrophages and the absence of lymphocytosis) in the second case.

Mavridou et al. [27] described CT findings of RB-ILD with smoking bronchial wall thickening and centrilobular emphysema in addition to ground-glass opacities

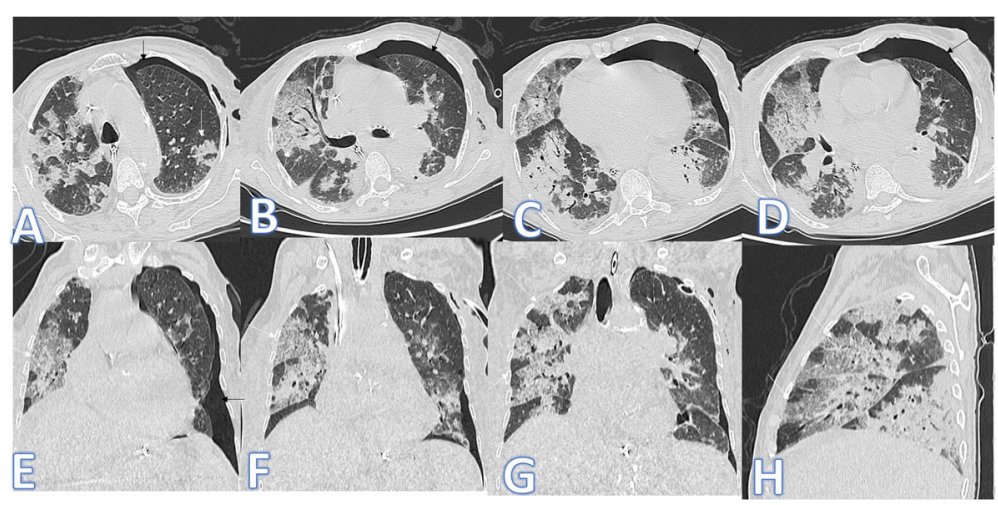

Fig. 13 A 72-year-old female patient presented with severe dyspnea with desaturation. She was intubated. CT chest revealed bilateral symmetric confluent patches of ground glass with crazy paving appearance mixed with consolidative patches with air bronchogram more in the lower lobes (white arrows) more on the right side. LT side mild pneumothorax was noted (black arrows). It was diagnosed as AIP after transbronchial biopsy 


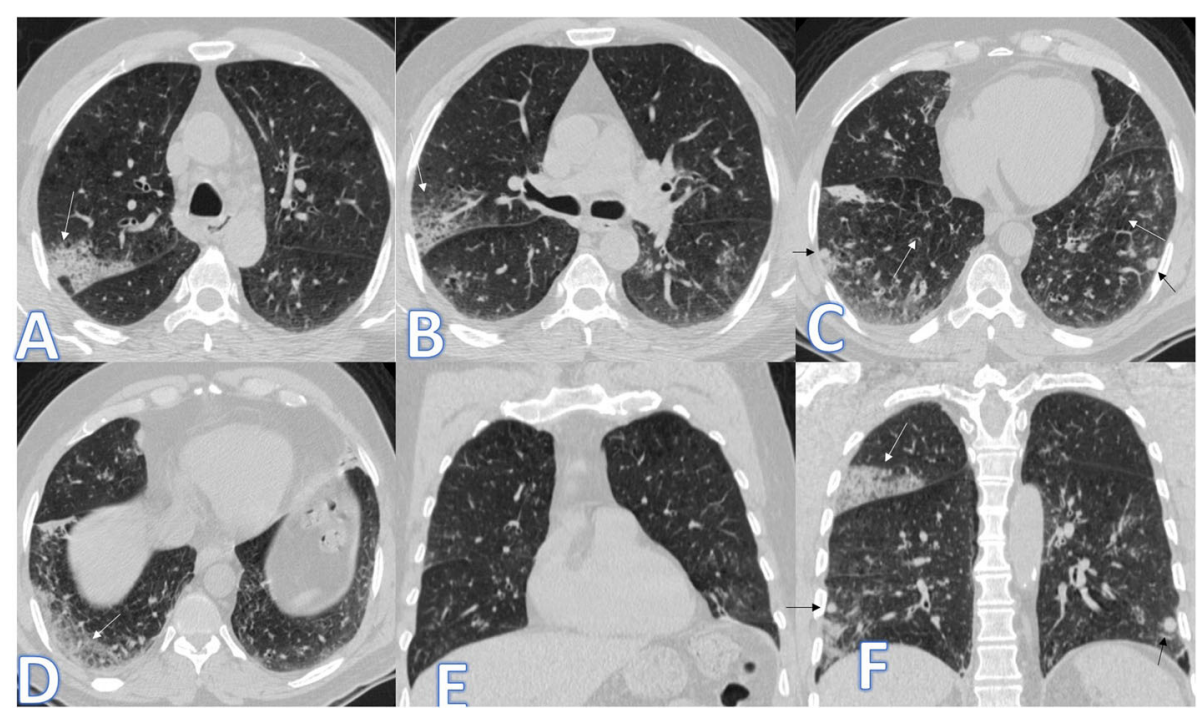

Fig. 14 A 65-year-old male patient presented with dyspnea and low-grade fever. CT chest showed bilateral scattered mainly peripheral consolidative patches with faint GGO (white arrows), associated bilateral basal interlobular septal thickening with small nodules (black arrows). The diagnosis was amidarone lung toxicity

with the slight upper zone predominance and ill-defined centrilobular nodules.

In this study, there was one case of pulmonary alveolar proteinosis (Fig. 11). It mimics CT features of COVID19 pneumonia with bilateral asymmetrical GGO with crazy-paving appearance, and the diagnosis was confirmed by bronchoalveolar lavage.
Holbert et al. [28] stated that crazy-paving pattern of PAP on CT is non-specific occurring in other diseases.

In this study, there was one case of known sarcoidosis presented with cough. CT showed bilateral patchy ground-glass appearance, but the presence of mild bronchiectatic changes of upper lobe predilection, multiple enlarged prevascular, pre/paratracheal, and hilar

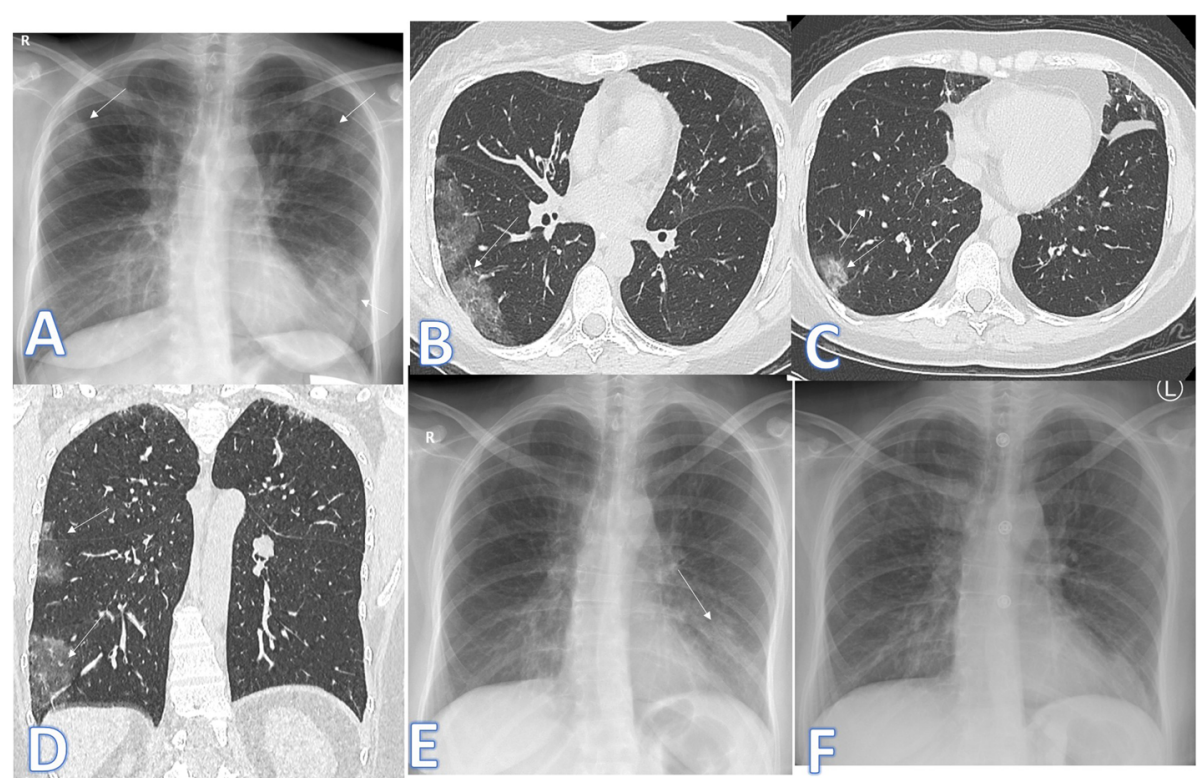

Fig. 15 A 38-year-old female patient with fever and cough. Initial X-ray (a) showed bilateral small air space opacities (arrows). On CT chest, there was bilateral peripheral GGO (arrows). X-ray done 1 year before (e), and there was a left lower lobe air space opacity which was resolved on X-ray (f) 6 months later (fleeting). The diagnosis was Loffler's pneumonia 


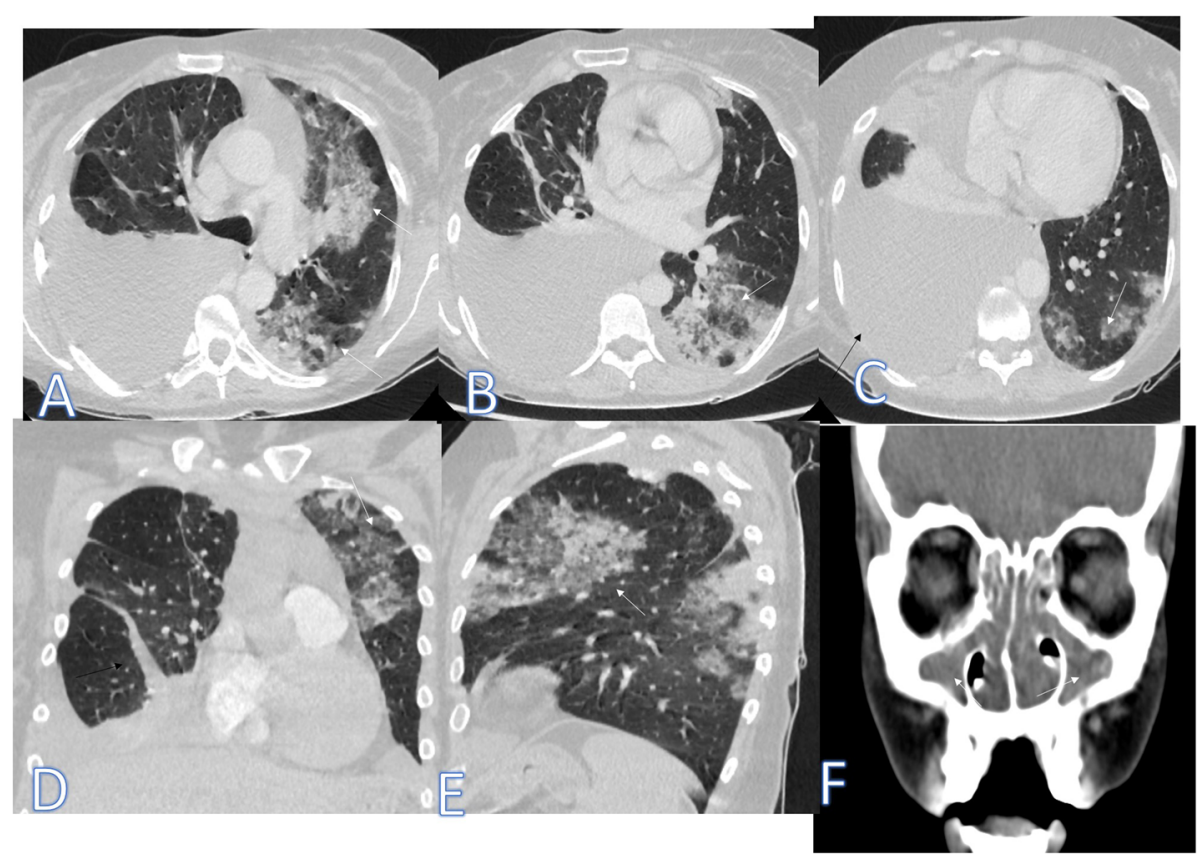

Fig. 16 A 39-year-old asthmatic female patient presented with shortness of breath with cough and dyspnea. CT showed multiple consolidative patches with GGO and crazy paving appearance (white arrows) and moderate right pleural effusion (black arrow). CT paranasal sinus (f) showed bilateral total opacifications of the sinus (arrow). The diagnosis was Churg-Strauss syndrome

LNS as well as the clinical history with no fever was the clue for the diagnosis of alveolar sarcoidosis (Fig. 12).

There was one case of acute interstitial pneumonitis (AIP) presented with severe dyspnea and desaturation; she was intubated. CT chest revealed bilateral asymmetric confluent patches of ground glass with crazy-paving appearance mixed with consolidative patches with air bronchogram more in the lower lobes. The presence of LT side mild pneumothorax was uncommon for COVID-19 pneumonia (Fig. 13). Bronchoalveolar lavage and transbronchial biopsy were done after exclusion of infectious cause.

Wittram et al. [29] described AIP or Hamman-Rich syndrome CT findings with ground-glass attenuation:

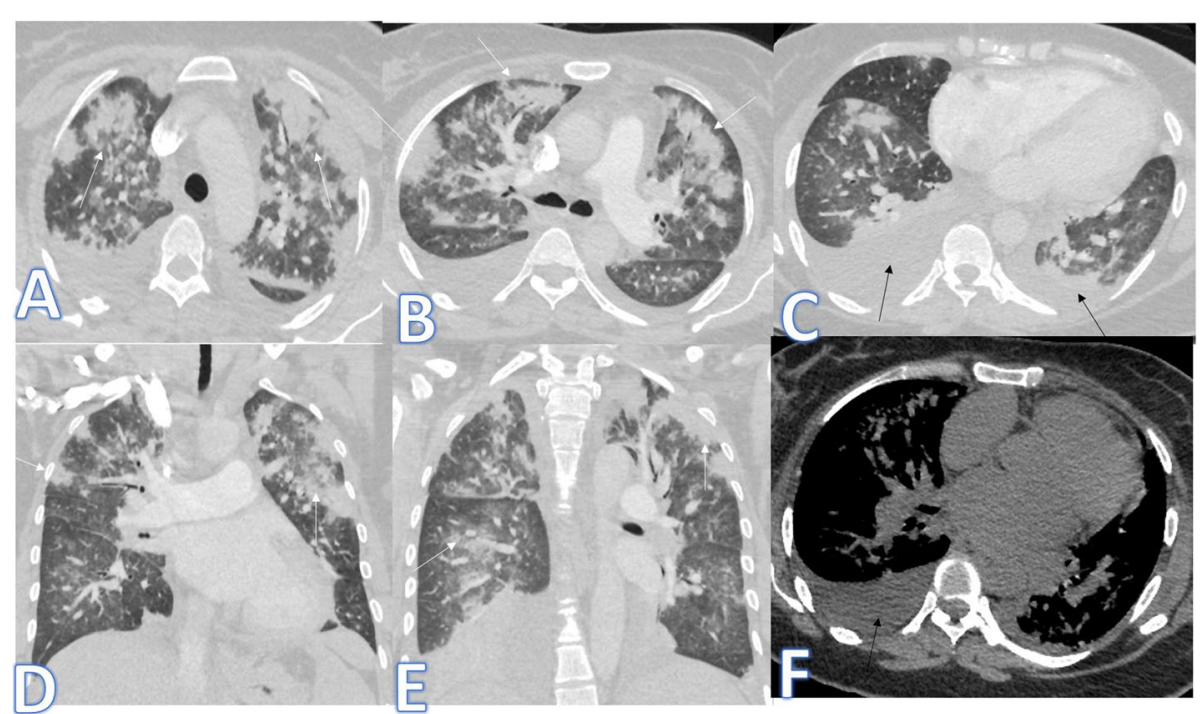

Fig. 17 A 49-year-old female patient presented with fever, cough, and dyspnea. CT showed bilateral confluent consolidative patches with upper lobe predilection (white arrows) and bilateral mild pleural effusions (black arrows); the diagnosis was drug rash with eosinophilia and systemic symptoms (DRESS) 
generally tend to be bilateral and symmetrical, traction bronchiectasis $(80 \%$ of cases during the course of the disease ), and parenchymal architectural distortion of the lung.

There was one patient in this study, presented with dyspnea and low-grade fever with CT chest showing bilateral scattered mainly peripheral consolidative patches with faint GGO, associated bilateral basal interlobular septal thickening with small nodules (Fig. 14). The patient had a history of amiodarone drug intake for 3 years. The patient was COVID-19 negative, and the presence of the pulmonary nodules and interlobular septal thickening was rare features of COVID-19. The case was confirmed by fiberoptic bronchoscopy with BAL and transbronchial biopsy to be amiodarone lung toxicity.

Wolkove et al. [30] stated that amiodarone lung toxicity is more common in patients exposed to amiodarone, usually for at least 6 months with risk factors like age over 60 years and daily dose $>400 \mathrm{mg}$. It has two main patterns, multiple peripheral GGO and interstitial fibrosis. One of the radiographic appearances of amiodarone pulmonary toxicity is the presence of peripherally located single or multiple pulmonary nodules, or mass-like opacities and may abut the pleura due to localized accumulation of the drug in an area of previous inflammation.

Another entity of diseases that may mimic COVID-19 is eosinophilic lung disease; we had 3 cases of the eosinophilic lung. The first case was Loffler's pneumonia (Fig. 15). The diagnosis was made due to fleeting opacities (on X-ray done 1 year before the clinical symptoms, there was left lower lobe air space opacity which was resolved on X-ray 6 months later indicating fleeting opacities), elevated eosinophilic count in BAL, peripheral blood eosinophilia, and high IgE level.

Jeong et al. [31] described Löffler syndrome or simple pulmonary eosinophilia on imaging as a fleeting, nonsegmental GGO which may be unilateral or bilateral peripheral predominance. Pleural effusions and lymphadenopathy are not features.

The second case of the eosinophilic lung was ChurgStrauss syndrome (Fig. 16) of asthmatic female patient presented with shortness of breath with cough and dyspnea. CT showed multiple consolidative patches with GGO and crazy-paving appearance, moderate right pleural effusion with extrapulmonary manifestations of pansinusitis, and arthritis, and it was confirmed by laboratory results of high eosinophils and IgE.

The etiology of Churg-Strauss syndrome may be allergic or immune pathogenesis for the disease with asthma, eosinophilia, and elevated serum IgE levels. It affects the lung followed by the skin. However, any organ can be involved. The most common thin-section CT findings include sub-pleural ground-glass opacity or consolidation with a lobular distribution, centrilobular nodules, bronchial wall thickening, and interlobular septal thickening and less commonly mediastinal or hilar lymphadenopathy, and pleural or pericardial effusion [31].

The third case of the eosinophilic lung (Fig. 17) was drug rash with eosinophilia and systemic symptoms (DRESS) with a history of drug intake (anticonvulsant), skin rash, fever, cough, and dyspnea. Bilateral confluent consolidative patches with upper lobe predilection, bilateral mild pleural effusions were seen on CT, and the diagnosis was confirmed by peripheral eosinophilia.

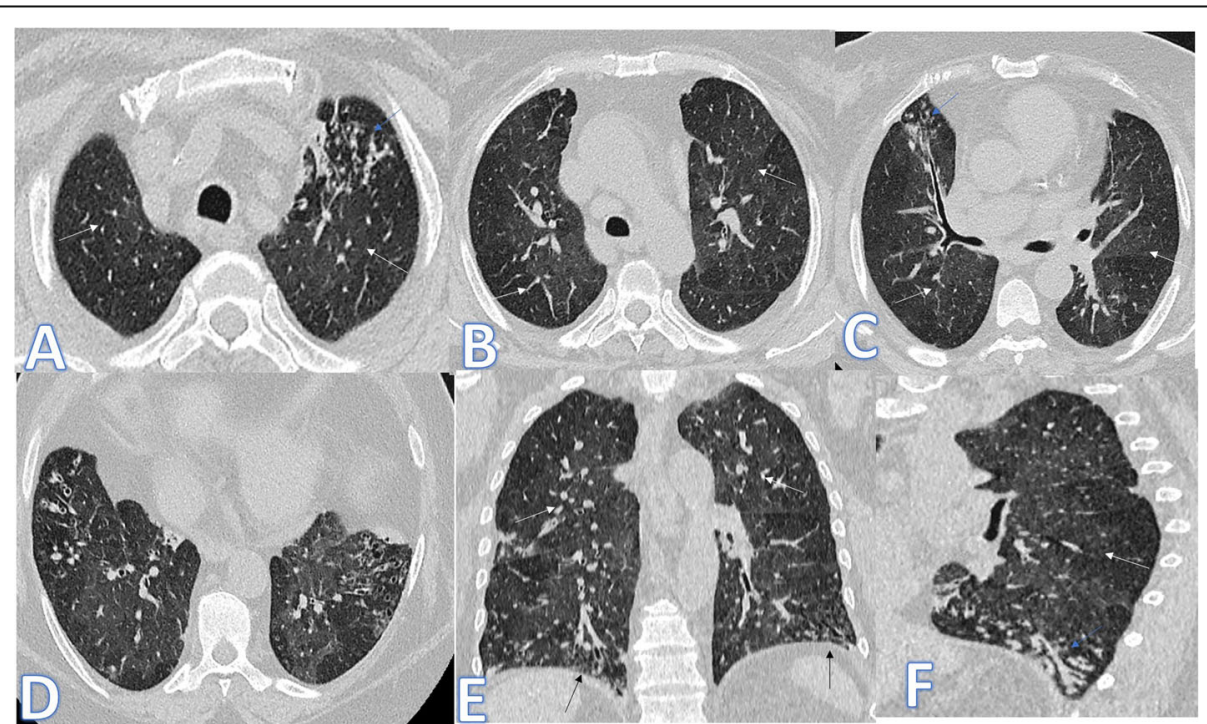

Fig. 18 A 61-year-old female patient with bronchial asthma presented with cough and wheezy chest. On CT, there were bilateral mosaic patches of GGO due to air trapping (white arrows) with left upper lobe tree-in bud and subsegmental atelectasis (blue arrows), peribronchial thickening, and bilateral mild basal bronchoectatic changes (black arrows) 


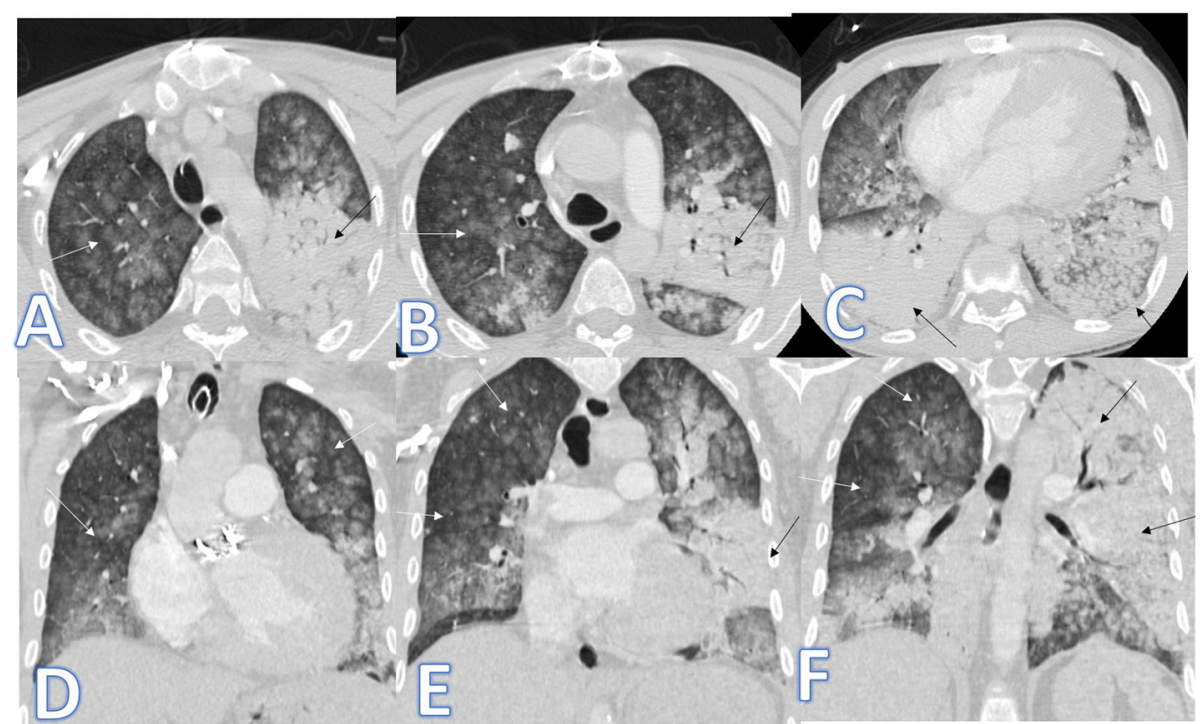

Fig. 19 A 32-year-old male patient with ESRD on dialysis presented with fever and cough. CT showed bilateral high-density ground glass centrilobular nodules (white arrows) due to metastatic pulmonary calcification occurring in renal failure. Associated left lung consolidative patches with air bronchogram (black arrows). The diagnosis was metastatic calcification with superadded lung infection

The drug rash with eosinophilia and systemic symptoms or DRESS syndrome typically manifests as a skin rash, fever, and lymphadenopathy with variable internal organ involvement and represents a druginduced hypersensitivity reaction. Chest CT findings are non-specific but may show diffuse multifocal infiltrative opacification [32].

There were 3 cases of bronchial asthma in this study (Fig. 18) presented with bilateral mosaic patches of GGO due to air trapping seen, but there was left upper lobe tree-in-bud, subsegmental atelectasis (due to superadded infection), and bilateral mild basal bronchoectatic changes; such features are uncommon for COVID-19.

In this study, there was a patient with ESRD on dialysis presented with fever and cough. CT showed bilateral high-density ground-glass centrilobular nodules due to metastatic pulmonary calcification occurring in renal failure. Associated left lung consolidative patches with air bronchogram (Fig. 19). The diagnosis was metastatic calcification with superadded bacterial lung infection based on clinical history with laboratory testing.

\section{Conclusion}

The spectrum of CT imaging findings in COVID-19 pneumonia is wide that could be contributed by many other diseases making the interpretation of chest CTs nowadays challenging to differentiate between different diseases having the same signs and act as deceiving simulators in the era of COVID-19.

\section{Abbreviation}

nCoV: Novel coronavirus; RT-PCR: Real-time polymerase chain reaction; CT: Computed tomography; NPS: Nasopharyngeal swab; GGO: Ground glass opacification; UIP: Usual interstitial pneumonia; NSIP: Non-specific interstitial pneumonia; ARDS: Acute respiratory distress syndrome; DAD: Diffuse alveolar damage; COP: Cryptogenic organizing pneumonia; SLE: Systemic lupus erythematosus; HRCT: High-resolution computed tomography; ILD: Interstitial lung disease; RB-ILD: Respiratory bronchiolitis interstitial lung disease; PAP: Pulmonary alveolar proteinosis; HP: Hypersensitivity pneumonitis; CHP: Chronic hypersensitivity pneumonitis; BAL: Bronchoalveolar lavage; AIP: Acute interstitial pneumonia; PET: Positron emission tomography; DRES S: Drug rash with eosinophilia and systemic symptoms; ESRD: End-stage renal disease

\section{Acknowledgements}

We would like to thank all the people who helped us in this work including the clinicians and technicians.

\section{Authors' contributions}

The authors AM Motawea, S Omar, and R Yasin equally shared contributions as regards writing of the manuscript, the collection and analysis of the data, and revising the final manuscript. The authors have read and approved the final manuscript.

\section{Funding}

Self-funding.

\section{Availability of data and materials \\ All data and materials are available.}

\section{Ethics approval and consent to participate}

The study protocol was approved by the local ethics committee (HSC Ethical Committee). All study procedures were performed in accordance with the ethical standards laid down in the 1964 Declaration of Helsinki and its later amendments.

No available ethics committee's reference number.

A written consent was taken from all patients prior to the study to be included in our study.

\section{Consent for publication}

A written consent was taken from all patients prior to the study for publication. 


\section{Competing interests}

No competing interests.

Received: 25 August 2020 Accepted: 4 December 2020

Published online: 05 January 2021

\section{References}

1. Song F, Shi N, Shan F et al (2020) Emerging 2019 novel coronavirus (2019nCoV) Pneumonia. Radiology 295(1):210-217

2. WHO Director-General's opening remarks at the media briefing on COVID19-11 March 2020. https://www.who.int/dg/speeches/detail/who-directorgeneral-s-opening- remarks-at-the-media-briefing-on-covid-19-11-march-2 020. (accessed March 22, 2020).

3. Coronavirus Update (Live): 629,450 Cases and 28,963 deaths from COVID-19 virus outbreak - worldometer n.d. https://www.worldometers.info/ coronavirus. (accessed March 28, 2020).

4. Zhou F, Yu T, Du R et al (2020) Clinical course and risk factors for mortality of adult inpatients with COVID-19 in Wuhan, China: a retrospective cohort study. The Lancet 395(10229):1054-1062

5. Rubin GD, Ryerson CJ, Haramati LB et al (2020) The role of chest imaging in patient management during the COVID-19 pandemic: a multinational consensus statement from the Fleischner society. Radiology 296:172-180

6. Corman VM, Landt O, Kaiser M et al (2020) Detection of 2019 nove coronavirus (2019-nCoV) by real-time RT-PCR. Euro Surveillance 25(3): 2000045

7. Fang $Y$, Zhang $H$, Xie J et al (2020) Sensitivity of chest CT for COVID-19: comparison to RT-PCR. Radiology 296:115-117

8. Ai T, Yang Z, Hou H et al (2020) Correlation of chest CT and RT-PCR testing in coronavirus disease 2019 (COVID-19) in China: a report of 1014 cases. Radiology 296:32-40

9. Zu ZY, Jiang MD, Xu PP et al (2020) Coronavirus disease 2019 (COVID-19): a perspective from China. Radiology 296:15-25

10. Wang Y, Dong C, Hu Y et al (2020) Temporal changes of $C T$ findings in 90 patients with COVID-19 pneumonia: a longitudinal study. Radiology 296:55-64

11. Li X, Zeng W, Chen $\mathrm{H}$ et al (2020) CT imaging changes of corona virus disease 2019 (COVID-19): a multi-center study in Southwest China. J Transl Med 18:154

12. Chung M, Bernheim A, Mei X et al (2020) CT imaging features of 2019 novel coronavirus (2019-nCoV). Radiology 295:202-207

13. Bai HX, Hsieh B, Xiong $Z$ et al (2020) Performance of radiologists in differentiating COVID-19 from viral pneumonia on chest CT. Radiology 296:46-54

14. Luo L, Luo Z, Jia Y et al (2020) CT differential diagnosis of COVID-19 and non-COVID-19 in symptomatic suspects: a practical scoring method. BMC Pulmonary Medicine 20:129

15. Tanaka N, Matsumoto T, Kuramitsu T et al (1996) High-resolution CT findings in community-acquired pneumonia. J Comput Assist Tomogr 20:600-608

16. Elicker BM, Webb WR (2013). Fundamentals of high-resolution lung Ct. Lippincott Williams \& Wilkins. 1st edition ISBN:1451184085. Publisher: Lippincott Williams \& Wilkins, (December 29, 2012) Reviewed in the United States.

17. Grudzinska FS, Brodlie M, Scholefield BR et al (2020) Neutrophils in community-acquired pneumonia: parallels in dysfunction at the extremes of age. Thorax 75(2):164-171

18. Komiya K, Ishii H, Murakami J et al (2013) Comparison of chest computed tomography features in the acute phase of cardiogenic pulmonary edema and acute respiratory distress syndrome on arrival at the emergency department. Journal of thoracic imaging. 28(5):322-328

19. Zompatori M, Ciccarese F, Fasano L (2014) Overview of current lung imaging in acute respiratory distress syndrome. Eur Respir Rev 23(134):519-530

20. Ferguson ND, Fan E, Camporota L et al (2012) The Berlin definition of ARDS: an expanded rationale, justification, and supplementary material. Intensive Care Med 38(10):1573-1582

21. Oikonomou A, Prassopoulos P (2011) CT imaging of blunt chest trauma. Insights into imaging 2(3):281-295

22. Wallis A, Spinks K (2015) The diagnosis and management of interstitial lung diseases. BMJ 350. https://www.google.com/url?sa=t\&rct=j\&q=\&esrc= $s \&$ source $=$ web $\& c d=\& c a d=r j a \& u a c t=8 \& v e d=2$ ahUKEwii5 $\mathrm{JrZ}-$ sDtAhUKSxUIHVqYDaUQFjAAegQIARAC\&url=https\%3A\%2F\%2Fwww.bmj. com\%2Fcontent\%2F350\%2Fbmj.h2072\%2Farticle-info\&usg=AOvVaw2 AvUa99WfYHLgyZ4jz9f0G.
23. Webb WR, Müller NL, Naidich DP (2008) High-resolution CT of the lung, 4th edn, ISBN:0781769094. Lippincott Williams \& Wilkins. https://www.google. $\mathrm{com} / \mathrm{url}$ ?sa $=\mathrm{t} \& \mathrm{rct}=\mathrm{j} \& \mathrm{q}=\&$ \&esrc $=\mathrm{s} \&$ source $=$ web $\& \mathrm{~cd}=\& \mathrm{cad}=\mathrm{rja} \&$ uact $=8 \& \mathrm{ved}=$ 2ahUKEwjt--LH-8DtAhXkoXEKHc2VDSIQFjAAegQIAhAC\&url=https\%3A\%2F\%2 Fwww.amazon.com\%2FHigh-Resolution-CT-Lung-Richard-Webb\%2Fdp\%2 F0781769094\&usg=AOvVaw1Oa1gCOAY8f7ArlHeyQbnQ.

24. Marten K, Schnyder P, Schirg E et al (2005) Pattern-based differential diagnosis in pulmonary vasculitis using volumetric CT. AJR Am J Roentgenol 184(3):720-733

25. Lacasse $Y$, Girard M, Cormier $Y$ (2012) Recent advances in hypersensitivity pneumonitis. Chest 142(1):208-217

26. Hirschmann JV, Pipavath SN, Godwin JD (2009) Hypersensitivity pneumonitis: a historical, clinical, and radiologic review. Radiographics 29(7): 1921-1938

27. Mavridou D, Laws D (2004) Respiratory bronchiolitis associated interstitial lung disease (RB-ILD): a case of an acute presentation. Thorax 59(10):910911

28. Holbert JM, Costello P, Li W et al (2001) CT features of pulmonary alveolar proteinosis. AJR Am J Roentgenol 176(5):1287-1294

29. Wittram C, Mark EJ, Mcloud TC (2003) CT-histologic correlation of the ATS/ ERS 2002 classification of idiopathic interstitial pneumonias. Radiographics. 23(5):1057-1071

30. Wolkove N, Marc Baltzan M (2009) Amiodarone pulmonary toxicity. Can Respir J 16(2):43-48

31. Jeong YJ, Kim KI, Seo IJ et al (2007) Eosinophilic lung diseases: a clinical, radiologic, and pathologic overview. Radiographics 27(3):617-637

32. Ohkoh T, Müller NL, Akira M et al (2000) Eosinophilic lung diseases: diagnostic accuracy of thin-section CT in 111 patients. Radiology 216(3): $773-780$

\section{Publisher's Note}

Springer Nature remains neutral with regard to jurisdictional claims in published maps and institutional affiliations.

\section{Submit your manuscript to a SpringerOpen ${ }^{\circ}$ journal and benefit from:}

- Convenient online submission

- Rigorous peer review

- Open access: articles freely available online

- High visibility within the field

- Retaining the copyright to your article

Submit your next manuscript at $>$ springeropen.com 